\title{
Senescence induced by RECQL4 dysfunction contributes to Rothmund-Thomson syndrome features in mice
}

\author{
H Lu' ${ }^{1}$, EF Fang ${ }^{1}$, P Sykora ${ }^{1}$, T Kulikowicz ${ }^{1}$, Y Zhang ${ }^{2}$, KG Becker ${ }^{2}$, DL Croteau ${ }^{1}$ and VA Bohr ${ }^{*}$ 1
}

Cellular senescence refers to irreversible growth arrest of primary eukaryotic cells, a process thought to contribute to agingrelated degeneration and disease. Deficiency of RecQ helicase RECQL4 leads to Rothmund-Thomson syndrome (RTS), and we have investigated whether senescence is involved using cellular approaches and a mouse model. We first systematically investigated whether depletion of RECQL4 and the other four human RecQ helicases, BLM, WRN, RECQL1 and RECQL5, impacts the proliferative potential of human primary fibroblasts. BLM-, WRN- and RECQL4-depleted cells display increased staining of senescence-associated $\beta$-galactosidase (SA- $\beta$-gal), higher expression of $\mathrm{p} 16^{\mathrm{INK} 4 \mathrm{a}}$ or/and $\mathrm{p} 21^{\mathrm{WAF} 1}$ and accumulated persistent DNA damage foci. These features were less frequent in RECQL1- and RECQL5-depleted cells. We have mapped the region in RECQL4 that prevents cellular senescence to its $\mathrm{N}$-terminal region and helicase domain. We further investigated senescence features in an RTS mouse model, Recql4-deficient mice (Recql4 ${ }^{\mathrm{HD}}$ ). Tail fibroblasts from Recq $14^{\mathrm{HD}}$ showed increased SA- $\beta$-gal staining and increased DNA damage foci. We also identified sparser tail hair and fewer blood cells in Recq $4^{\mathrm{HD}}$ mice accompanied with increased senescence in tail hair follicles and in bone marrow cells. In conclusion, dysfunction of RECQL4 increases DNA damage and triggers premature senescence in both human and mouse cells, which may contribute to symptoms in RTS patients.

Cell Death and Disease (2014) 5, e1226; doi:10.1038/cddis.2014.168; published online 15 May 2014

Subject Category: Cancer

Cellular senescence is a state of irreversible cell-cycle arrest or loss of proliferative capacity, initially described in normal cultured human cells. ${ }^{1}$ Cells can senesce because of a response to persistent DNA damage from various endogenous or exogenous stresses, including replication-induced telomere shortening, DNA-damaging agents and high expression of certain oncogenes. ${ }^{2,3}$ Senescent cells are characterized by a number of features, including irreversible growth arrest, enlarged morphology, increased activity of senescence-associated $\beta$-galactosidase (SA- $\beta$-gal), high levels of $\mathrm{p} 16^{\text {INK4a }}(\mathrm{p} 16)$ or/and p21 ${ }^{\text {WAF1 }}$ (p21), DNA segments with chromatin alterations reinforcing senescence (DNA-SCARS), secretion of cytokines, chemokines, growth factors and proteases (also referred to as senescence-associated secretary phenotype (SASP)) and altered gene expression., ${ }^{3,4}$ Senescence may be an alternative response to stressors that could cause cellular transformation. ${ }^{5}$ SASP may stimulate tissue repair or regeneration, age-dependent features and tumor growth. ${ }^{3}$ Senescent cells are more common in tissues from older than younger mammals, ${ }^{6}$ and this may contribute to aging by limiting tissue renewal. ${ }^{7}$

RecQ helicases are a highly conserved protein family that unwind DNA from $3^{\prime}$ to $5^{\prime}$ and have important roles in DNA replication, repair, homologous recombination and telomere maintenance. ${ }^{8-10}$ Escherichia coli cells express one RecQ helicase, whereas human and other mammalian species express five RecQ helicases: RECQL1, BLM, WRN, RECQL4 and RECQL5. These RecQ helicases have partially overlapping and non-redundant roles in maintaining genome stability. Defects in BLM or WRN cause Bloom syndrome (BS) or Werner syndrome (WS), respectively, whereas defects in RECQL4 cause Rothmund-Thomson syndrome (RTS), RAPADILINO (RAPA) and Baller-Gerold syndrome (BGS). ${ }^{11}$ Fibroblasts from WS patients show premature senescence in culture as depletion of WRN with siRNA in human primary fibroblasts triggers cellular senescence. ${ }^{12-15}$ Defects in BLM also increase cellular DNA damage, leading to a senescencelike phenotype in primary fibroblasts. ${ }^{14,16}$ BLM-deficient lymphoblast cells show high sister chromatin exchange frequency and this feature is believed to promote premature senescence, which might accelerate aging symptoms in BS patients. ${ }^{17}$ However, the role of RECQL1, RECQL4 and RECQL5 in prevention of senescence is unclear.

RECQL4 is less well-characterized than BLM or WRN. ${ }^{18}$ RECQL4 has weaker helicase activity and less stringent substrate preferences than WRN or BLM. ${ }^{19-21}$

\footnotetext{
${ }^{1}$ Laboratory of Molecular Gerontology, Biomedical Research Center, National Institute on Aging, National Institutes of Health, Baltimore, MD 21224, USA and ${ }^{2}$ Gene Expression and Genomics Unit, National Institute on Aging, National Institutes of Health, MD 21224, USA

*Corresponding author: VA Bohr, Laboratory of Molecular Gerontology, Biomedical Research Center, National Institute on Aging, National Institutes of Health, Room 06B133A, 251 Bayview Boulevard, Suite 100, Baltimore, MD 21224-6825, USA. Tel: +1 410558 8162; Fax: +1 410558 8157; E-mail: vbohr@ nih.gov Keywords: RecQ helicase; RECQ4; RECQL4; senescence; Rothmund-Thomson syndrome; premature aging Abbreviations: BGS, Baller-Gerold syndrome; BS, Bloom syndrome; DNA-SCARS, DNA segments with chromatin alterations reinforcing senescence; NLS, nuclear localization signal; p16, p16 ${ }^{\text {INK4a; }}$; 21, p21 ${ }^{\text {WAF1; }}$ PML, promyelocytic leukemia; RAPA, RAPADILINO; Recql4 ${ }^{\mathrm{HD}}$, Recql4-deficient mice; RTS, Rothmund-Thomson syndrome; SA- $\beta$-gal, senescence-associated $\beta$-galactosidase; SASP, senescence-associated secretary phenotype; WS, Werner syndrome

Received 19.12.13; revised 27.2.14; accepted 05.3.14; Edited by G Melino
} 
RECQL4 interacts with the DNA replication machinery to have an important role in DNA replication initiation. ${ }^{22-24}$ RECQL4 also interacts with several DNA repair proteins, including RAD51, ${ }^{25} \mathrm{XPA}^{26}{ }^{26} \mathrm{FEN1} 1{ }^{27}$ APE $1,{ }^{27} \mathrm{Pol} \beta,{ }^{27} \mathrm{PARP}^{28}$ and BLM. ${ }^{10}$ Deficiency in RECQL4 increases sensitivity to DNAdamaging agents. ${ }^{10,25,26,29}$ RECQL4 interacts with the telomere shelterin proteins TRF1 and TRF2 and functions on telomeric D-loops, suggesting a role in telomere maintenance. ${ }^{30,31}$ RECQL4 is the only RecQ helicase reported to colocalize to the mitochondria, although its function there is still unclear. ${ }^{32,33}$

Mutations in RECQL4 are associated with RTS, BGS and RAPA, which share clinical features, including short stature, skeletal abnormalities and radial ray defects. ${ }^{11}$ RTS patients have skin disorders and skeletal abnormalities, as well as sparse hair. ${ }^{11} \mathrm{RTS}$ patients are prone to bone and skin cancer and hematological disorders, including leukopenia and aplastic anemia. ${ }^{11}$ However, the mechanisms underlying these features are poorly known. We hypothesized that a dysfunction in RECQL4 may trigger senescence, contributing to pathological features of RTS. Here, we systematically investigate the role of RECQL4 in maintaining proliferative potential in both human and mouse primary fibroblasts, as well as an RTS mouse model.

\section{Results}

Depletion of RECQL4, BLM or WRN induces cellular senescence in primary fibroblasts. To evaluate the roles of RecQ helicases in cellular senescence, the five RecQ helicases were individually depleted in normal human primary fibroblasts (GM05565). Approximately 90\% of RECQL $1,80 \%$ of BLM, $95 \%$ of WRN, $90 \%$ of RECQL4 and $80 \%$ RECQL5 was depleted with shRNA against each RecQ helicase, respectively (Figure 1a). Control cells expressed a randomized version of the shRNA targeting motif. ${ }^{34}$ SA- $\beta$-gal activity was measured in knockdown and control cells as an important marker of senescence. ${ }^{35}$ Approximately $80 \%$ of BLM-depleted cells and $90 \%$ of WRN-depleted cells showed positive SA- $\beta$-gal staining (Figures $1 \mathrm{~b}$ and $\mathrm{c}$ ), and expression of cell cycle inhibitors p16 and p21 also increased significantly in BLM- and WRNknockdown cells (Figures 1d and e), consistent with previous studies. $^{12,14}$ Likewise, $70 \%$ of RECQL4-depleted cells stained positively for SA- $\beta$-gal (Figure 1c) and p21 expression increased twofold (Figure 1e), reflecting that dysfunction of RECQL4 induced senescence in the primary fibroblasts. RECQL5-depleted cells displayed an intermediate senescence phenotype, with $37 \%$ of depleted cells expressing SA- $\beta$-gal, whereas RECQL1-depleted cells were similar to the control cells (Figure 1c). Similar experiments were performed in another primary fibroblast (GM00969), using siRNAs that target different regions for each of the RecQ genes. Quantitative PCR in these cell lines showed that $85-95 \%$ of each RecQ helicase was depleted (Supplementary Figure S1) and depletion of BLM, WRN, RECQL4 and RECQL5 was associated with increased staining for SA- $\beta$-gal (Supplementary Figure S1), similar to the cells treated with the shRNAs. Loss of BLM, WRN or RECQL4 in human primary fibroblasts greatly increased senescence, which is not dependent on replication-related telomere shortening, because depletion of any of them also triggered senescence in the telomerase-positive fibroblast BJ-5TA cells (Supplementary Figure S2).

In addition to the presence of SA- $\beta$-gal, knockdown of RECQL4, BLM or WRN also correlated with a reduced rate of cell proliferation. Cell growth was modestly affected by knockdown of RECQL1 or RECQL5 (Figure 1f). The results of staining with Annexin V/propidium iodide (PI) indicated no significant increase in apoptosis in RecQ helicase-deficient fibroblasts(Supplementary Figure S3), consistent with the observation that senescent cells are resistant to apoptosis. ${ }^{36}$ However, more cell death was observed in the cells with depletion of BLM, WRN or RECQL4 (Supplementary Figure S3), which may also contribute to disease pathology besides senescence.

Senescent cells are irreversibly arrested in the G1/G0 phase of the cell cycle. ${ }^{37}$ Knockdown of WRN, BLM, RECQL4 or RECQL5 caused a decrease in S-phase cells and accumulation of cells in G0/G1 (Figure 1g). Replicationinduced senescent cells usually arrest in $\mathrm{G} 1 / \mathrm{G} 2{ }^{38}$ These data may indicate that RecQ helicase knockdown cells experience stress-induced cell cycle arrest.

RecQ helicases participate in DNA base excision repair, a major DNA repair process for oxidative stress-induced DNA damage. ${ }^{10}$ We postulated that high oxygen tension $\left(20 \% \mathrm{O}_{2}\right)$ during typical cell culturing conditions could increase the load of oxidative DNA lesions in proliferating cells, leading to cellular senescence. ${ }^{3}$ To assess whether this contributed to the loss of cell viability observed above, RecQ-helicasedepleted cells were grown in $3 \%$ or $20 \% \mathrm{O}_{2}$, and SA- $\beta$-gal staining was quantified. As expected, fewer cells expressed SA- $\beta$-gal when the culture was maintained in $3 \% \mathrm{O}_{2}$ than $20 \%$ $\mathrm{O}_{2}$, regardless of the RecQ expression status (Figure 1h). However, approximately $50 \%$ of BLM-deficient cells, $80 \%$ of WRN-deficient cells and $60 \%$ of RECQL4-deficient cells still stained positively for SA- $\beta$-gal when grown in $3 \%$ oxygen (Figure 1h). Similar results were obtained in shRNA-RecQhelicase-depleted GM00969 cells (Supplementary Figure S4). Thus, even when cells are somewhat protected from oxidative stress by growth in low oxygen conditions, RECQL4 depletion induces senescence similar to the loss of BLM or WRN.

Increased persistent DNA damage in RecQ helicasedeficient fibroblasts. Stress-induced senescent cells harbor persistent DNA damage foci, called 'DNA-SCARS', and they can be indicated by colocation of DNA damage maker 53BP1 foci and promyelocytic leukemia (PML) nuclear bodies. ${ }^{4}$ Here, DNA-SCARS were measured in RecQhelicase-depleted fibroblasts. In accordance with the notion that persistent DNA damage is a major stimulus for cellular senescence, ${ }^{3}$ senescence in RecQ-helicase-depleted cells closely correlated with persistent cellular DNA damage markers. When exposed to $20 \% \mathrm{O}_{2}, 70 \%$ of RECQL4depleted cells carried three or more 53BP1/PML foci, compared with only $10 \%$ of the control cells (Figure 2). When cells were grown in $3 \% \mathrm{O}_{2}$, more than $50 \%$ of RECQL4-depleted and $10 \%$ of control cells carried three or more 53BP1/PML foci (Figure 2). RECQL4-depleted cells 
a

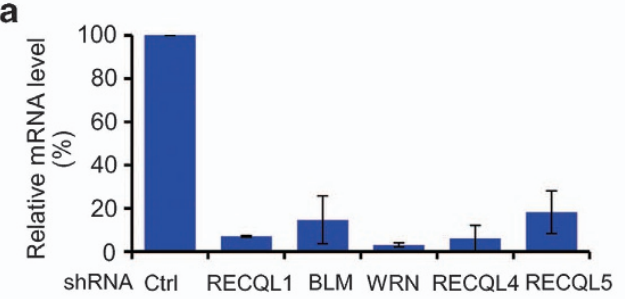

C

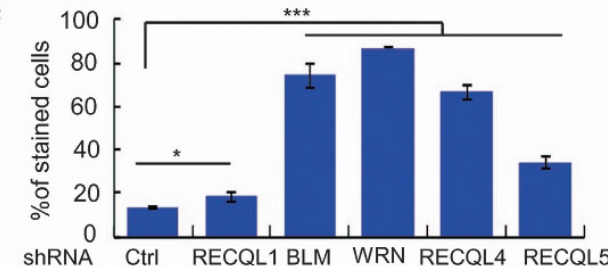

d
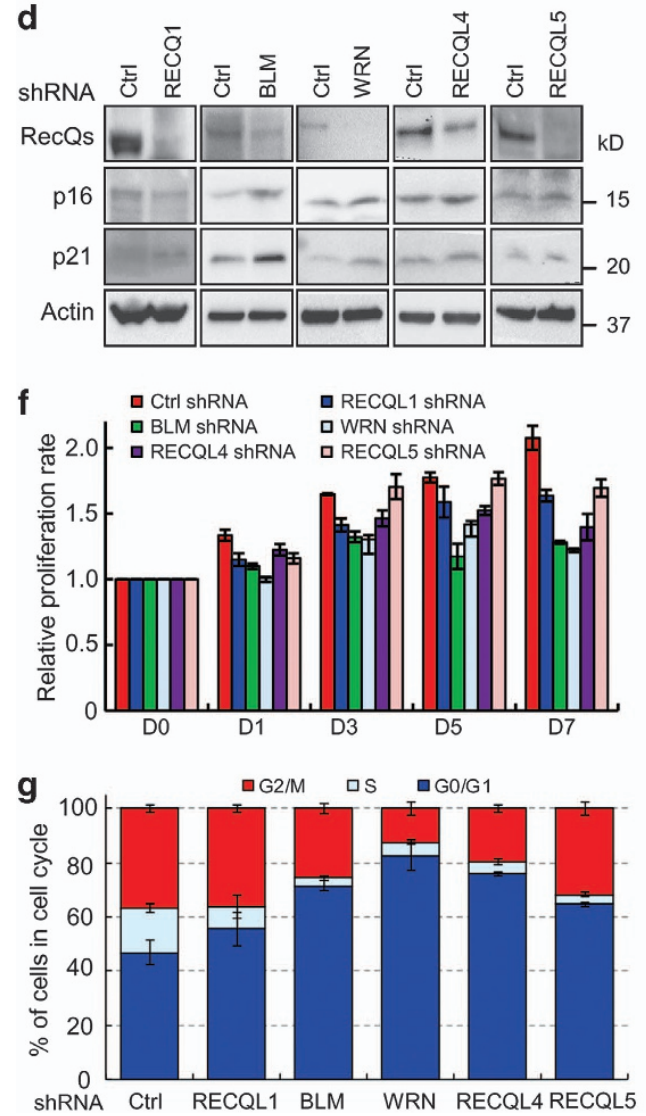

b

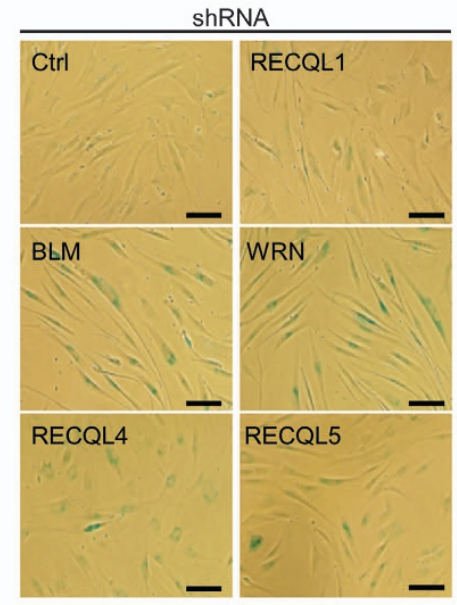

\section{h}

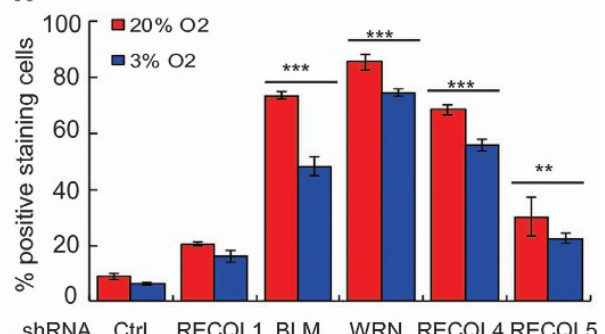

ShRNA Ctrl RECQL1 BLM WRN RECQL4 RECQL5

Figure 1 Knockdown of BLM, WRN or RECQL4 induces cellular senescence in primary fibroblast cells. Knockdown of each RecQ helicase by lentivirus-mediated shRNA in human primary fibroblast cells (GM05565, passage 11). (a) The mRNA levels of each RecQ helicase were measured by qPCR after shRNA-mediated knockdown. (b) SA- $\beta$-gal staining; (c) quantitation of positive SA- $\beta$-gal-stained cells. (d) Western blotting analysis for RecQ helicases, p16 and p21, as well as loading control $\beta$-actin; (e) quantitation of western blotting result; (f) cell proliferation was measured by WST-1. (g) Cell cycle analysis. (h) Quantitation of SA- $\beta$-gal staining of RecQ helicase-depleted cells and control cells under low-oxygen (3\%) or high-oxygen (20\%) culture conditions. All data here are from at least three independent replicates. ${ }^{\star} P<0.05 ;{ }^{\star \star} P<0.01 ;{ }^{* \star} P<0.001$

also had more cells with five or more $\gamma \mathrm{H} 2 \mathrm{~A} . \mathrm{X}$ foci than control, independent of oxygen tension during growth (Supplementary Figure S5). Similar results were obtained in BLM- or WRN-depleted cells (Figure 2 and Supplementary Figure S5). ${ }^{14}$ RECQL5 knockdown but not RECQL1 knockdown also correlated with increased 53BP1/PML foci (Figures $2 a$ and $b$ ). These data indicate that depletion of RECQL4, BLM, WRN or RECQL5 increases the load of persistent DNA damage in human primary fibroblasts, which can also be aggravated by oxidative stress. In RECQL4depleted cells, ATM is activated by phosphorylation at serine 1981, p53 is activated by phosphorylation at serine 15 and H2A.X showed increased serine 139 phosphorylation (Figure 2c). Taken together, these data indicate that RECQL4 depletion activated the DNA damage response via ATM. 
a
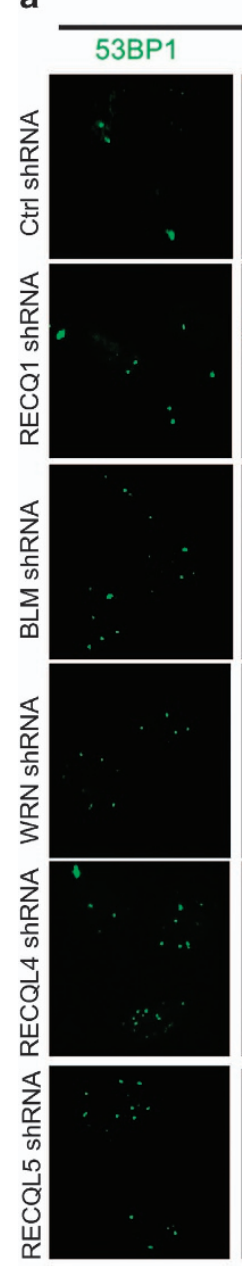

b

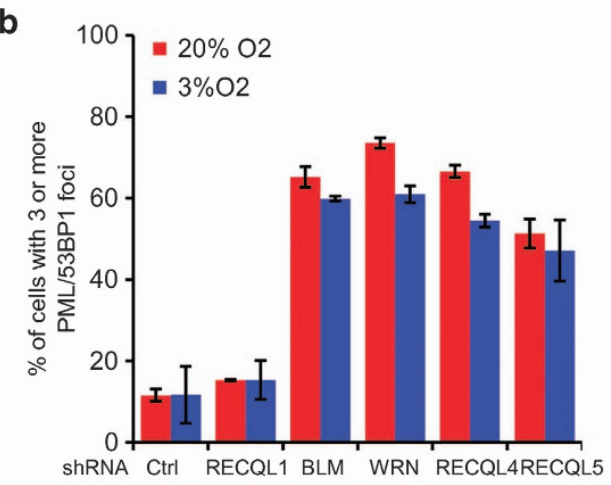

$20 \% \mathrm{O}_{2}$
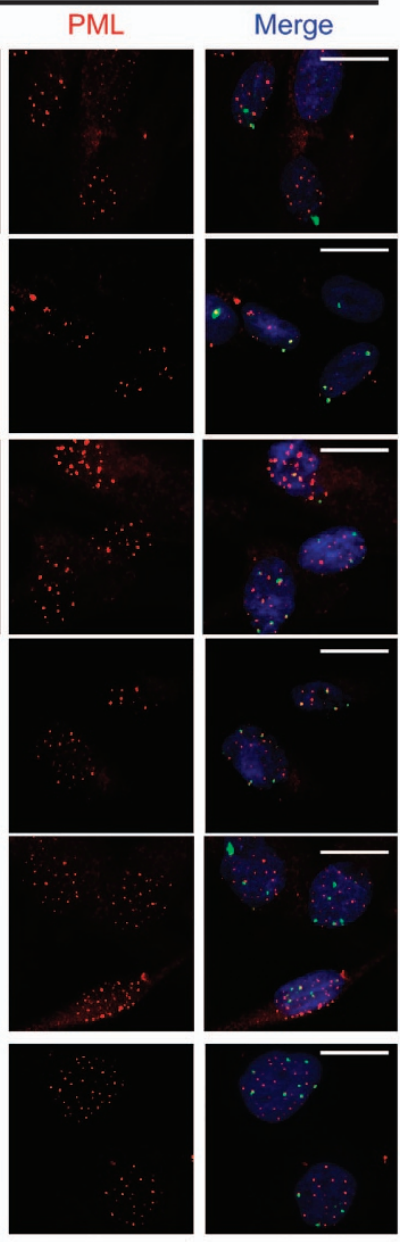

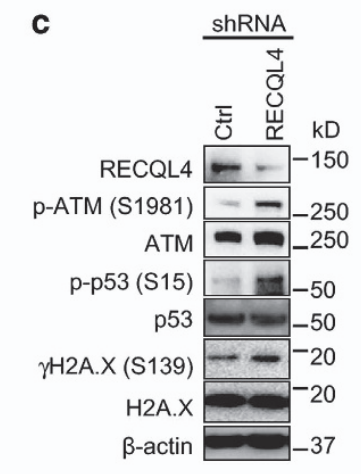

$3 \% \mathrm{O}_{2}$
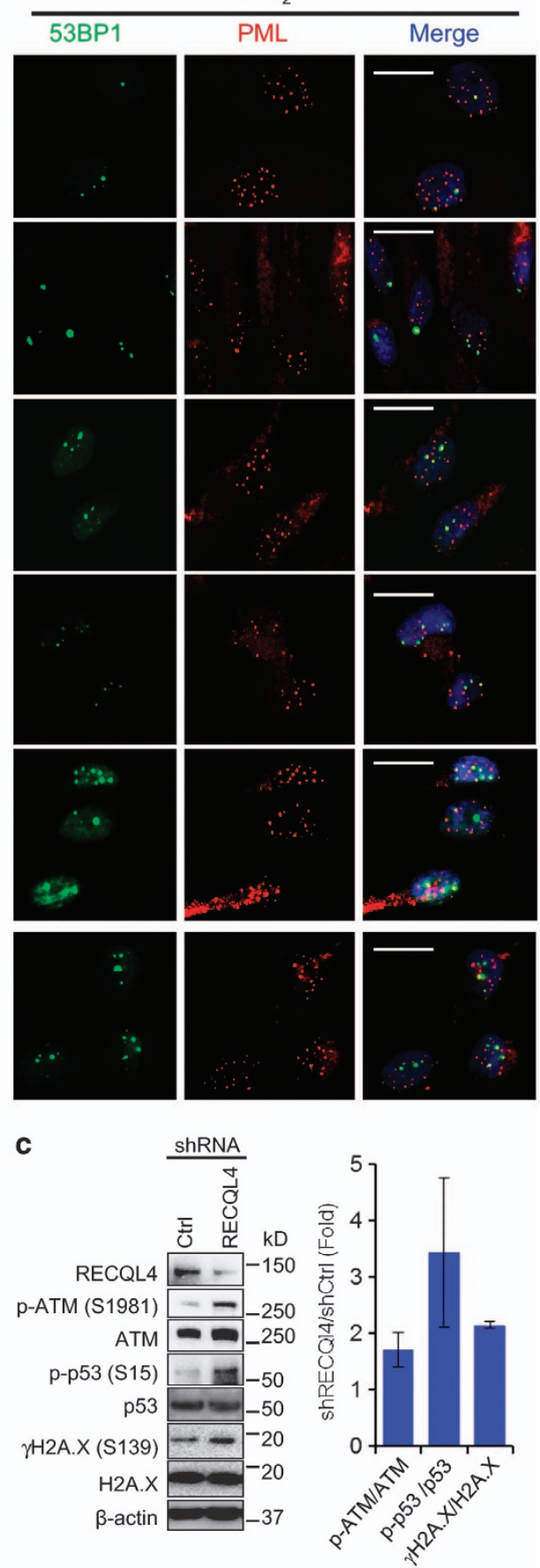

Figure 2 Increased persistent DNA damage in primary fibroblast cells after RecQ helicase loss. RecQ helicases were depleted by lentivirus-mediated shRNA in human primary fibroblast cell line GM05565 at passage 11. (a) The indicated cell lines were immunostained with $53 \mathrm{BP} 1$ antibody and PML antibody. Bar scale is $20 \mu \mathrm{m}$. (b) Quantitation of colocalized 53BP1 foci and PML nuclear bodies in the indicated cell lines as in a. (c) Western blotting analysis for ATM, p53 and H2A.X as well as their phosphorylated forms in RECQL4-depleted GM05565 fibroblasts. Ratios of phosphorylated ATM, p53 and H2AX relative to their total expression levels were quantified

Both the N-terminal region and the helicase domain of RECQL4 are required to prevent cellular senescence. To explore the effect of RECQL4 depletion further, plasmids expressing 3X-Flag-tagged truncated fragments of RECQL4 were transiently transfected into RECQL4-depleted cells, and the cellular phenotype was reassessed (Figure 3a). Western blotting showed that over $90 \%$ of endogenous
RECQL4 was depleted using siRNA targeting the $3^{\prime}$-UTR of RECQL4 (Figure 3b). Plasmids expressing 3X-Flag-tagged fragments of RECQL4 were transfected into the GM05565 fibroblasts one day before siRNA knockdown of endogenous RECQL4. Expression of endogenous RECQL4 and RECQL4 fragments was quantified (Figure 3c). Approximately $80 \%$ of knockdown cells, $10 \%$ of control cells and $20 \%$ of knockdown 
a

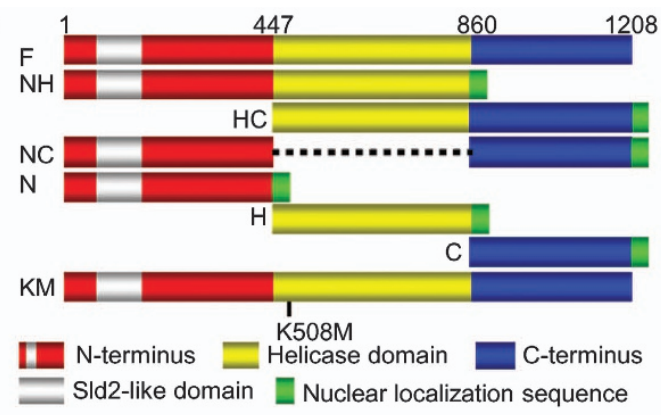

b

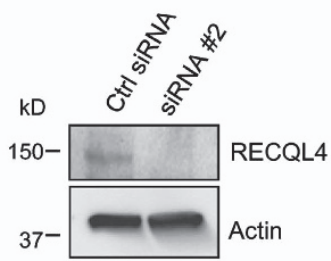

C

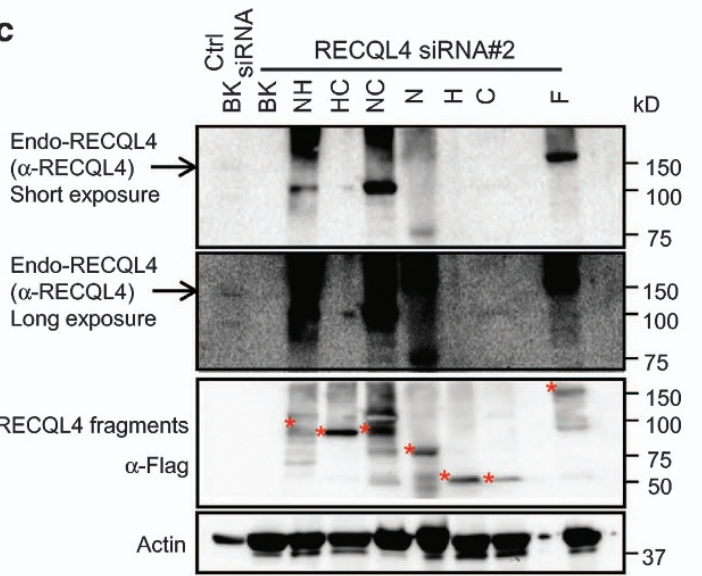

d

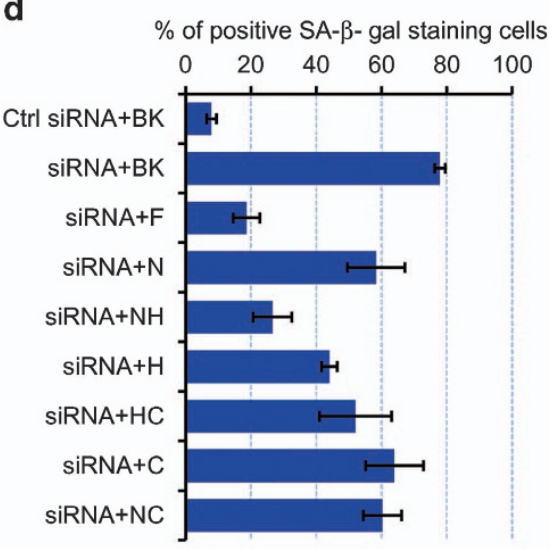

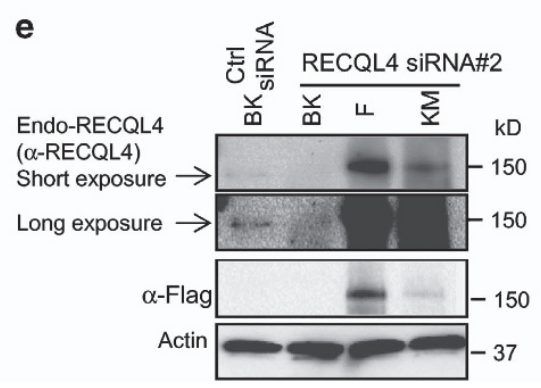

$\mathbf{f}$

$\%$ of positive SA- $\beta$ - gal staining

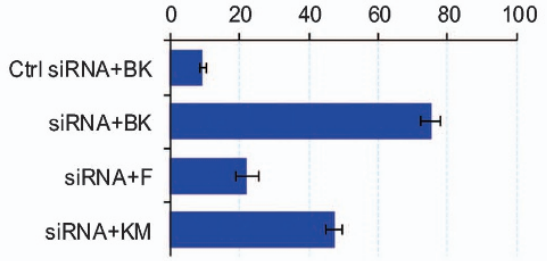

Figure 3 The N terminus and the helicase domain of RECQL4 are required to prevent cellular senescence. (a) Schematic diagram of plasmids harboring different domains of RECQL4; F, full-length RECQL4; NH, RECQL4 fragment from 1-860 amino-acid residues (AA) with nuclear location signal sequence (NLS) at the C-terminal; HC, RECQL4 fragment from 447-1208 with NLS-tagged at C-terminal; NC, RECQL4 fragment combining 1-447 AA and 860-1208AA with NLS at C-terminal; N, RECQL4 fragment from 1-447 AA with NLS at C-terminal; H, RECQL4 fragment from 447-860 AA with NLS at C-terminal; C, RECQL4 fragment from 860-1208 with NLS at C-terminal; KM, full-length RECQL4 with mutation K508M. (b) Western blot showing knockdown efficiency of the siRNA targeting the $3^{\prime}$ UTR of RECQL4. (c) Western blotting analysis of endogenous RECQL4 level and expression of RECQL4 fragments in GM05565 cells. BK, pCMV-Tag4A-3XFlag vector. The bands with star symbol indicate 3XFlag tagged RECQL4 and its truncated fragments. (d) Senescence was measured by SA- $\beta$-gal staining in fibroblast cells with endogenous RECQL4 depleted and RECQL4 fragments expressed. (e) Western blotting analysis of endogenous RECQL4 level and expression of RECQL4 wild-type protein and RECQL4 K508M (KM) mutant in GM05565 cells. (f) Senescence was measured by SA- $\beta$-gal staining in fibroblast cells with endogenous RECQL4 depleted and RECQL4 wild-type and RECQL4K508M mutant expressed

cells expressing full-length 3X-Flag-tagged RECQL4 stained positively for SA- $\beta$-gal (Figure $3 \mathrm{~d}$ ), indicating significant complementation of the knockdown phenotype by plasmidencoded RECQL4. RECQL4-depleted cells expressing an RECQL4 fragment containing the $\mathrm{N}$-terminal and helicase domains (NH fragment) were also partially complemented as there was $28 \%$ positive staining for SA- $\beta$-gal (Figure $3 d$ ). Cells expressing the $\mathrm{N}$-terminal fragment, the helicase domain, the C-terminal domain or other partial domain combinations were less effective in rescuing the phenotype of the RECQL4-depleted cells. Because this result suggests that the helicase domain of RECQL4 is essential for complementing the phenotype of RECQL4-depleted cells, RECQL4-depleted cells were also transfected with plasmid expression RECQL4 K508M (KM), previously shown to lack helicase activity. ${ }^{21}$ Even without siRNA-mediated depletion of endogenous RECQL4, western analysis reveals much greater expression of both full-length and mutant 3X-Flagtagged RECQL4 (Figure 3e). However, while 78\% RECQL4depleted cells stained for SA- $\beta$-gal, only $22 \%$ or $47 \%$ of cells expressing 3X-Flag-tagged full-length or K508M RECQL4, respectively, expressed SA- $\beta$-gal (Figure $3 \mathrm{f}$ ). This suggests that the helicase activity is required for RECQL4 to fully prevent cellular senescence. 
a

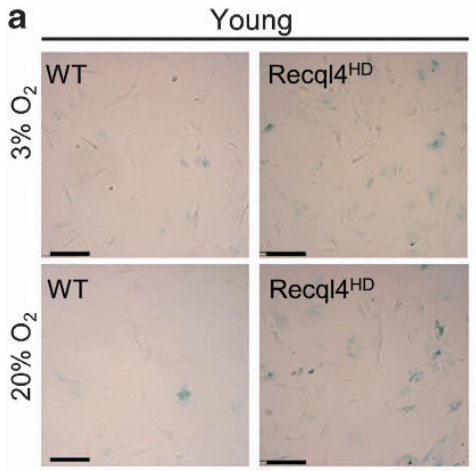

b
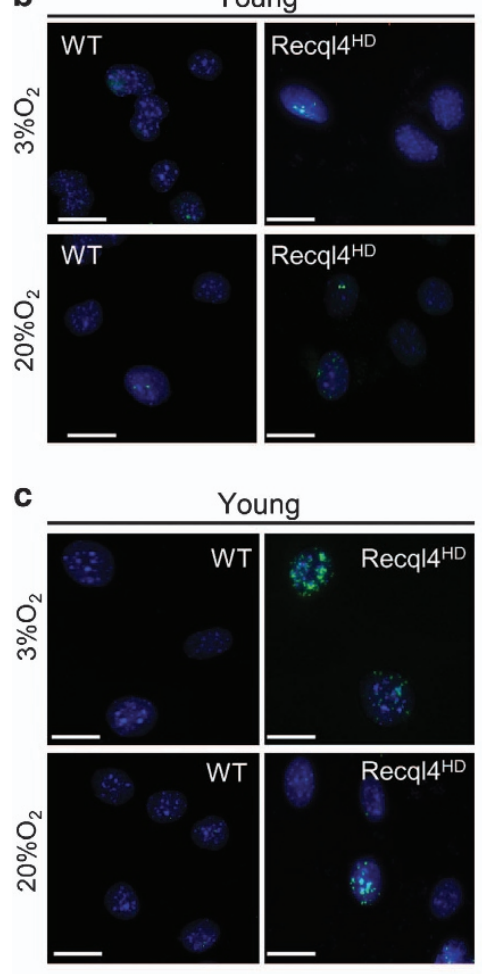

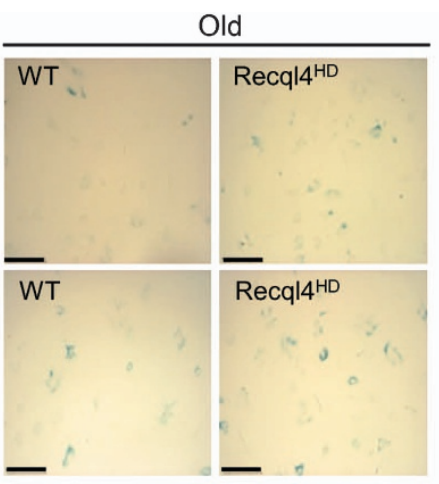

Old
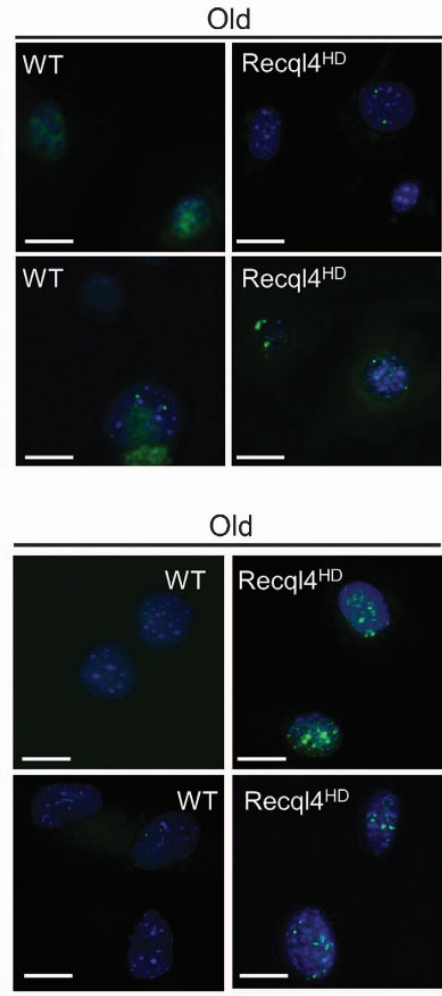

Old

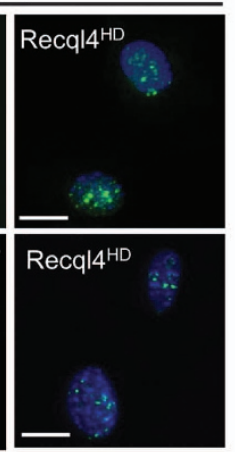

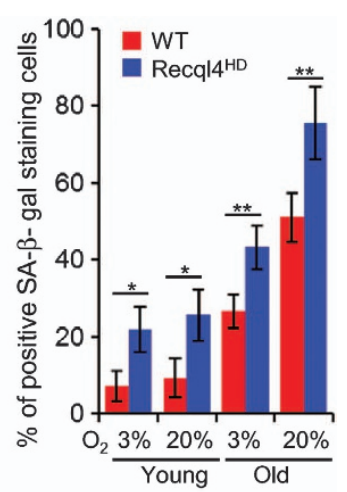
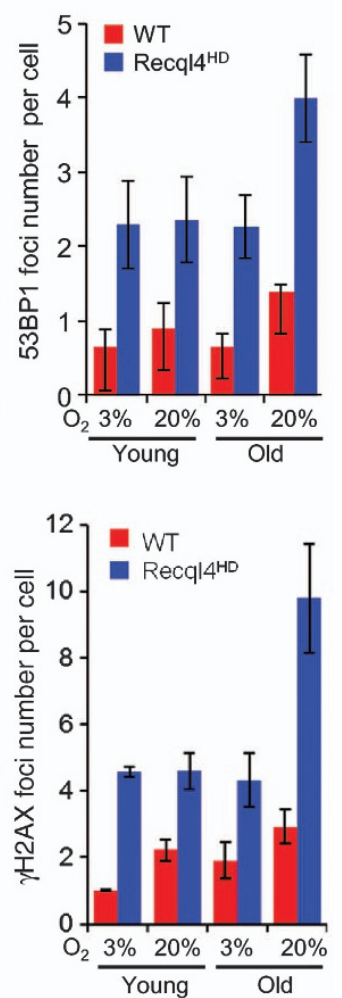

Figure 4 Increased cellular senescence and DNA damage in primary fibroblast cells from tails of Recql4HD mice. Fibroblast cells were extracted from young (5-month old) and old (12-month old) wild-type (WT) and helicase-domain-deleted (Recql4HD) mice. (a) Senescence was measured by SA- $\beta$-gal staining in both wild-type and Recql4 ${ }^{\mathrm{HD}}$ fibroblast cells under low-oxygen (3\%) or high-oxygen concentration culture conditions. ${ }^{\star} P<0.05 ;{ }^{* \star} P<0.01$. The bar indicates $150 \mu \mathrm{M}$ in a. DNA damage was measured by both 53BP1 foci (b) and $\gamma \mathrm{H} 2 \mathrm{~A} . \mathrm{X}$ foci number (c) in fibroblast cells grown in low-oxygen (3\%) or high-oxygen (20\%) culture conditions. The bars $\mathbf{b}$ and $\mathbf{c}$ indicate $20 \mu \mathrm{M}$

\begin{abstract}
Markers of senescence in tail fibroblasts from Recql $4^{\mathrm{HD}}$ mice. To determine the in vivo role of RECQL4, senescence features were extended to a mouse model for RTS in which the helicase domain is deleted in the endogenous Recql4 gene (Recql4-deficient mice (Recql $\left.4^{\mathrm{HD}}\right)$ ). ${ }^{39} \mathrm{SA}-\beta$-gal staining was performed in primary tail fibroblasts at early passage from 5- and 12-month-old Recql4 ${ }^{\mathrm{HD}}$ and sibling wild-type mice. Recql $4{ }^{\mathrm{HD}}$ fibroblasts expressed more SA- $\beta$-gal than wild-type fibroblasts. When grown at $20 \% \quad \mathrm{O}_{2}, 74 \%$ of fibroblasts from 12-month-old Recql $4^{\mathrm{HD}}$ cells stained positive, whereas only half of the wild-type cells stained positive (Figure 4a). A similar difference was seen when cells from 5-month-old Recql4 ${ }^{\mathrm{HD}}$ mice (25\%) were compared with wildtype siblings (9\%) (Figure 4a). The percentage of positive cells was smaller at lower $\mathrm{O}_{2}$ conditions, but still showed
\end{abstract}

more staining in Recql $4^{\mathrm{HD}}$ cells $(21 \%$ and $44 \%$ of the fibroblasts for young and old mice, respectively) than in wildtype cells ( $7 \%$ and $20 \%$ of the cells from young and old mice, respectively) (Figure 4a). In addition, the average number of 53BP1 foci was approximately threefold higher under 3\% oxygen and fourfold higher under $20 \%$ oxygen in cells from old Recql $4^{\mathrm{HD}}$ cells compared with cells from old wild-type cells (Figure $4 b$ ). The average number of $\gamma \mathrm{H} 2 \mathrm{~A}$.X foci per cell was two- or threefold more in Recql $4^{\mathrm{HD}}$ cells than in wild-type cells (Figure 4c). Similarly, the fibroblasts from young Recql $4^{\mathrm{HD}}$ mice also showed more DNA damage indicated by 53BP1 foci and $\gamma \mathrm{H} 2 \mathrm{~A}$.X foci (Figures $4 \mathrm{~b}$ and $\mathrm{c}$ ). These data suggest that more severe DNA damage was present in Recql $4^{\mathrm{HD}}$ mouse cells, which may then explain the higher percentage of senescent cells. 
a

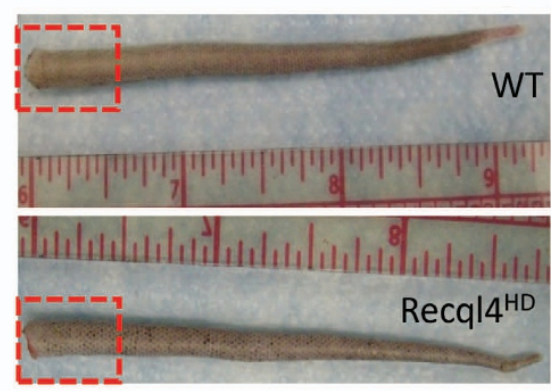

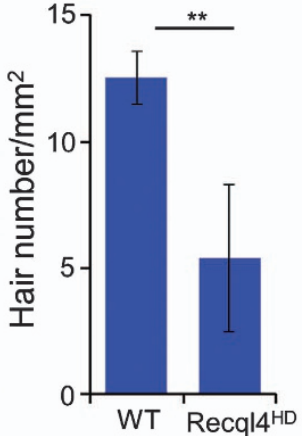

b

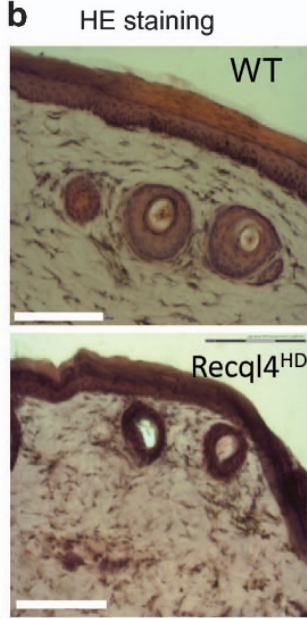

C $\quad$ SA- $\beta$-gal staining
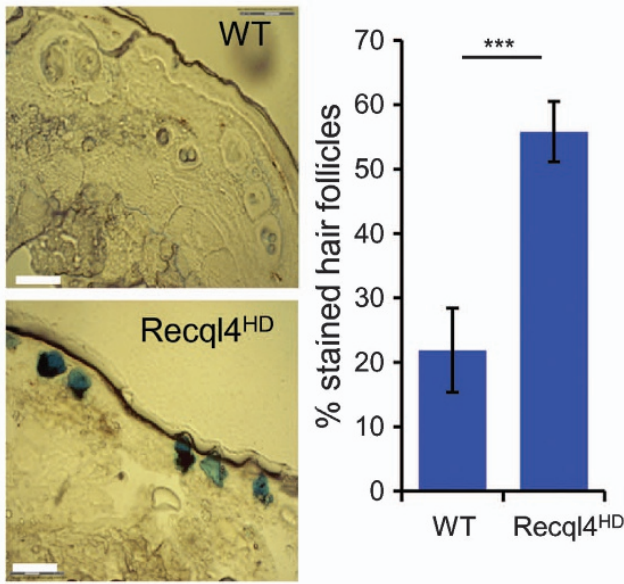

d
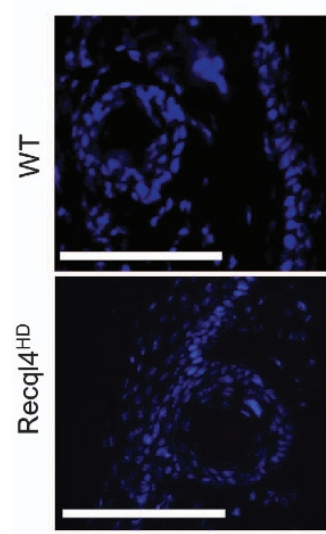

$53 \mathrm{BP} 1$

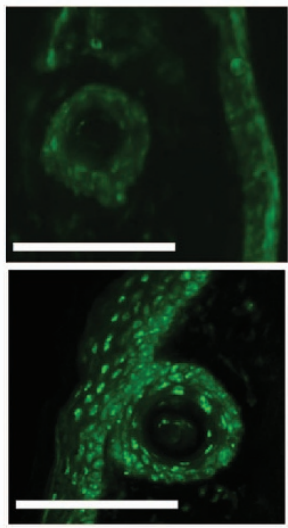

Merge

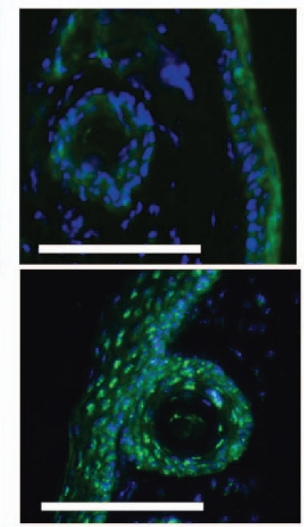

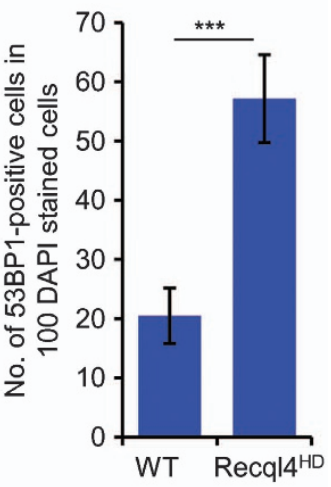

Figure 5 Increased senescence in tail hair follicles in Recq $14^{\mathrm{HD}}$ mice. Three pairs of wild-type and RTS male mice at the age of $\sim 40$ weeks were used. (a) Hair loss on the tails of RTS mice. H\&E staining (b) and SA- $\beta$-gal staining (c) were performed on frozen tail sections. (d) Increased DNA damage in tail hair follicles as assessed by expression of 53BP1. Quantitation was performed by comparing 53BP1-positive hair follicle cells per 100 DAPI-stained cells. ${ }^{\star \star} P<0.01 ;{ }^{* \star} P<0.001$. Bar indicates $150 \mu$ m

More cellular senescence in hair follicles in tails of RTS mice. As reported, 12-month-old Recql4 ${ }^{\mathrm{HD}}$ mice demonstrate a hypo-/hyperpigmented skin phenotype on their tails (Figures $5 \mathrm{a}$ and b). ${ }^{39}$ In addition, we observed less tail hair on Recql $4^{\mathrm{HD}}$ mice than in wild-type mice (Figure $5 \mathrm{a}$ ), as reported for another RTS mouse model. ${ }^{40}$ To investigate if senescence triggered by Recql4 mutation has a role in sparse hair, tail sections from Recql4 mutant mice as well as wild-type mice were screened for SA- $\beta$-gal staining. Approximately $55 \%$ of hair follicles on Recql4 ${ }^{\mathrm{HD}}$ tails stained positively for SA- $\beta$-gal (twofold more than in wild-type mice)
(Figure 5b). Moreover, 53BP1 immunofluorescence staining on tail sections showed that more 53BP1 accumulated in the tail cells of Recql4 ${ }^{\mathrm{HD}}$ mice, indicating increased DNA damage in these cells (Figure $5 \mathrm{c}$ ). These data are consistent with the idea that loss of mouse Recql4 helicase leads to higher levels of DNA damage and senescence in proliferating mouse tissues in vivo, which may account for the sparse hair on mutant mouse tails.

Hematological disorder and increased senescent bone marrow cells in Recql4 ${ }^{\mathrm{HD}}$ mice. Hematological disorders 
have been reported in some RTS patients. ${ }^{11}$ However, no hematological analysis was reported in the RTS mouse models. Thus, three 4-month-old Recql $4^{\mathrm{HD}}$ and four matched wild-type mice were submitted for blood analysis. Many blood cell types were significantly less abundant in Recql $4^{\mathrm{HD}}$ mice than in wild-type mice (Table 1), including white blood cells, red blood cells, lymphocytes and monocytes. As RECQL4 is reported to be highly expressed in bone marrow (http://www.genecards.org/cgi-bin/carddisp.pl?gene=RECQL4), the phenotype of bone marrow cells was further examined in

Table 1 Blood cell counts from samples of Recql $4^{\mathrm{HD}}$ and wild-type mice ${ }^{\mathrm{a}}$

\begin{tabular}{lcrr}
\hline Cell type & \multicolumn{1}{c}{$\begin{array}{c}\text { WT } \\
\text { (mean } \pm \text { S.D.) }\end{array}$} & $\begin{array}{c}\text { Recql4 } \\
\text { (mean } \pm \text { S.D.) }\end{array}$ & P-value \\
\hline WBC $\left(10^{3} / \mu \mathrm{l}\right)$ & $7.70 \pm 1.06$ & $4.13 \pm 0.43$ & 0.0016 \\
RBC $\left(10^{7} / \mu \mathrm{l}\right)$ & $9.58 \pm 0.38$ & $7.73 \pm 0.10$ & 0.0016 \\
Platelet $\left(10^{3} / \mu \mathrm{l}\right)$ & $833.50 \pm 85.07$ & $738.67 \pm 6.11$ & 0.0558 \\
PMNs $\left(10^{3} / \mu \mathrm{l}\right)$ & $1.03 \pm 0.41$ & $0.73 \pm 0.07$ & 0.1162 \\
Lymphocytes $\left(10^{3} / \mu \mathrm{l}\right)$ & $6.42 \pm 0.79$ & $3.32 \pm 0.37$ & 0.0008 \\
Monocytes $\left(10^{3} / \mu \mathrm{l}\right)$ & $0.21 \pm 0.02$ & $0.07 \pm 0.02$ & 0.0004 \\
Eosinophils $\left(10^{2} / \mu \mathrm{l}\right)$ & $0.25 \pm 0.44$ & $0.01 \pm 0.01$ & 0.2741 \\
Basophils $\left(10^{2} / \mu \mathrm{l}\right)$ & $0.02 \pm 0.04$ & $0.00 \pm 0.00$ & 0.1866
\end{tabular}

Abbreviations: PMNs, polymorphonuclear leukocytes; RBC, red blood cells; S.D., standard deviation; WBC, white blood cell

${ }^{\mathrm{a}}$ Four wild-type mice and three Recql4 mutant Recql4 ${ }^{\mathrm{HD}}$ mice at the age of 4 months were used in the experiment two 4-month-old male Recql $4^{\mathrm{HD}}$ and two matched wild-type mice. The number of SA- $\beta$-gal-positive cells was sixfold higher $(13 \%)$ in bone marrow from Recql4 ${ }^{\mathrm{HD}}$ mice than in bone marrow from wild-type mice (Figure 6a). Additionally, the expression of p21 protein was threefold higher in the mutant cells, compared with the wild-type mice (Figure 6b). DNA-SCARS were further investigated in these cells and the results showed that about $30 \%$ of Recql $4^{\mathrm{HD}}$ bone marrow cells harbors at least one colocalized 53BP1 foci and PML nuclear body, compared with only $5 \%$ of wild-type cells, indicating that more persistent DNA damage exists in the mutant cells (Figure 6c). These data together demonstrate that mutation of Recql4 in mice causes senescence of bone marrow cells.

\section{Discussion}

In this work, we present evidence for the involvement of RECQL4 deficiency in induced cellular senescence. We compared the severity of the senescence by knockdown of all the five human RECQ helicases in an isogenic background, and unveiled the significance of BLM, WRN and RECQL4 and, to a lesser degree, RECQL5 in the prevention of cellular senescence. The conclusion that RECQL4 depletion leads to senescence was supported by increased SA- $\beta$-gal staining, enhanced expression of p16 and p21, slow cell proliferation with G0/G1 cell cycle arrest and accumulated persistent DNA a
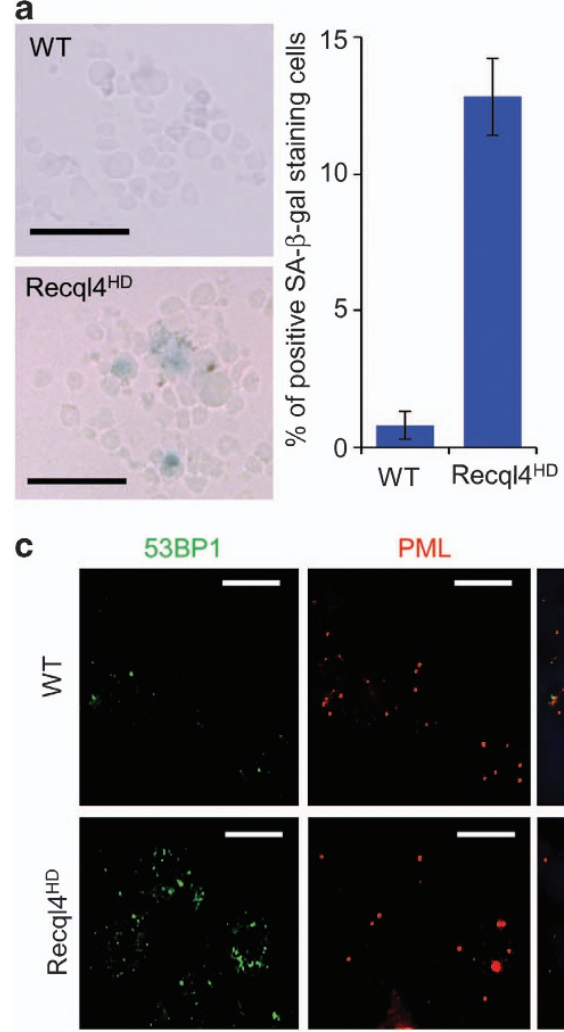

b
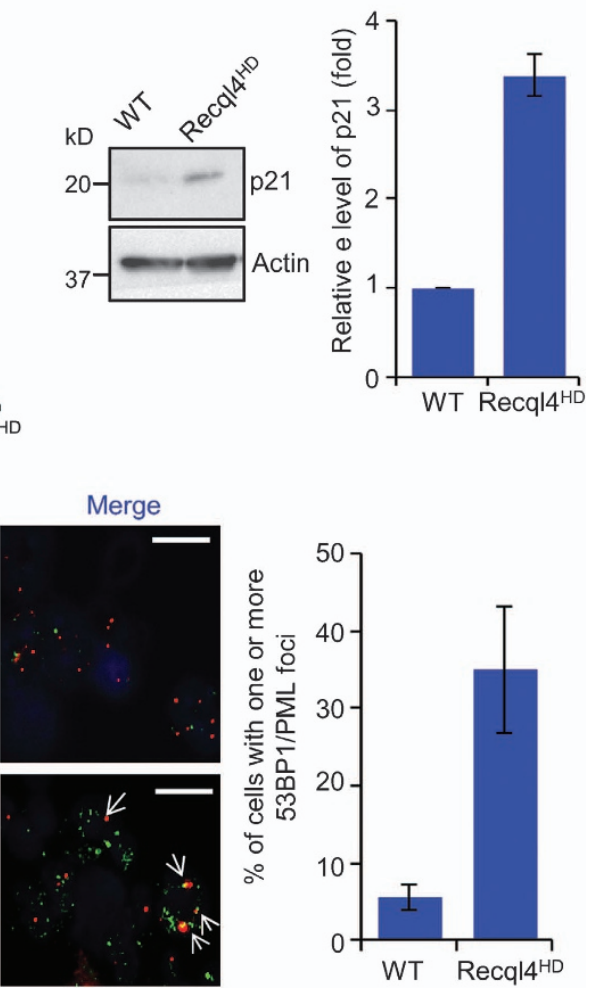

Figure 6 Increased senescence and persistent DNA damage in bone marrow cells from Recql ${ }^{\mathrm{HD}}$ mice. (a) Senescence of bone marrow cells from two pairs of sibling wild-type and RTS mice at the age of 4 months was measured by SA- $\beta$-gal staining. The bar indicates $150 \mu \mathrm{M}$. (b) Expression of p21 was investigated by western blotting. (c) DNA-SCARS were identified by immunostaining bone marrow cells with p53 and PML antibodies. The bar indicates $20 \mu \mathrm{M}$ 
damage foci. Characterization of Recql $4^{\mathrm{HD}}$ mice showed that dysfunction of Recql4 in vivo causes sparser tail hair and fewer blood cells, a phenotype that may be attributed to higher senescence of hair follicles and bone marrow cells, respectively, in this mouse model. These findings may provide insight into some clinical features of RTS patients.

The increased persistent DNA damage and senescence seen in RECQL4-, BLM- and WRN-depleted cells may be due to an increase in initiation of damage or a decrease in DNA repair. It has been shown that BLM participates in replication restart as well as damaged end processing and resolution of Holliday junctions. ${ }^{41,42}$ Thus, the absence of BLM results in greater DNA damage due to replication stress and persistent damage due to decreased DNA repair. Because the RecQ helicases share a conserved helicase domain, ${ }^{42}$ the DNA damage phenotype seen in BLM-, WRN- and RECQL4deficient cells may be partially attributed to this domain. This is further supported by our finding that RECQL4 lacking a functional helicase domain failed to complement depletion of endogenous RECQL4 by siRNA.

Despite the common helicase domain, results for RECQL5 or RECQL1 depletion were significantly different than for depletion of BLM, WRN or RECQL4. RECQL5-depleted cells displayed an intermediate phenotype, whereas RECQL1depleted cells were most similar to control cells. These differences may be due to slight differences in the conserved helicase domains or differences in non-conserved regions of the proteins. RECQL5 has an important role in transcription and DNA replication and repair. ${ }^{43}$ Although RECQL5 is not associated with a specific human disease, Recql5 mice are prone to tumor development. ${ }^{44}$ RECQL1 may be a backup for other RecQ helicases and may be less important in normal cells. However, primary embryonic fibroblasts from a Recq/1null mouse model show increased aneuploidy, spontaneous chromosomal breakage and elevated sister chromosome exchanges, ${ }^{45}$ indicating that Recql1 is required for genome stability. Further experiments should be carried out to address the differences among the RecQ helicases in normal human primary cells.

The transcriptomic analysis of RecQ helicase-depleted fibroblasts was examined by microarray gene expression (Supplementary Table S1), and gene set enrichment analysis revealed that a number of pathways were similarly affected in all RecQ helicase-deficient cells except RECQL1, including two telomere-related pathways, oxidative phosphorylation and electron transport chain pathways, as well as Huntington's disease, diabetes, Alzheimer's disease and Parkinson's disease pathways (Supplementary Figures S6 and S7). Packaging of telomere ends and telomere maintenance were highly upregulated pathways in the three disease-associated RecQ-deficient cell lines, and most of the affected genes are histone proteins in these pathways and not canonical telomere shelterin proteins. We considered that the upregulated transcriptional levels of these histones may be a response to DNA damage induced by the absence of BLM, WRN or RECQL4. We showed that the induction of senescence increased in RecQ helicase-depleted telomerasepositive fibroblast, BJ-5TA (Supplementary Figure S2), thus telomere shortening is unlikely the main mechanism whereby these proteins induce senescence. Thus, damage throughout the genome, including at telomeres, likely does promote senescence.

Recently, primary RTS fibroblasts were reported to have activated p38 MAP kinase, which is important for senescence growth arrest. ${ }^{46}$ However, the replicative lifespan of RTS fibroblast cells is not markedly shorter than that of control cells. ${ }^{46}$ Nonetheless, the RTS and the control cell lines used were not isogenic, as they were from donors with different genetic backgrounds and different starting passage numbers. These factors may explain the finding that the RTS cells only showed a modest deceased lifespan compared with controls. ${ }^{46}$ In this study, to exclude the influence of genetic background, we used shRNA or siRNA to deplete RECQL4 in two human primary fibroblasts and also investigated the role for RECQL4 in senescence in mice.

We find that both the N-terminal region and the helicase domain are required to inhibit senescence in human primary fibroblasts. The N-terminal region is required for RECQL4 to participate in DNA replication initiation and cell viability. ${ }^{22,23,47}$ We propose that in the absence of the $\mathrm{N}$-terminal region of RECQL4, replication forks collapse and are not reinitiated and this induces severe DNA damage provoking a persistent DNA damage response, which could activate the senescence pathway. However, the N-terminal region of RECQL4 is not sufficient to suppress senescence. Likewise, expression of only the helicase domain does not suppress senescence, and thus only a combination of the $\mathrm{N}$-terminal and helicase domains are sufficient to prevent senescence. Recently, we showed loss of helicase activity in several RECQL4 patient protein variants, ${ }^{48,49}$ indicating that the helicase domain is required to prevent disease. Interestingly, the C-terminal region, containing the putative $\mathrm{RQC}$ domain, ${ }^{50}$ was not required to prevent senescence. Therefore, it is presently not clear what the function of the RECQL4 C terminus is; however, it does not seem to be crucial for DNA metabolism under normal growth conditions, but may be important for recruitment or response to exogenous DNA damage, like ionizing radiation. ${ }^{51}$

As reported previously and confirmed here, hyper-/hypopigmented skin was found on the tails of RTS mice. In addition, we documented sparser hair on mouse tails, a feature also seen in RTS patients. ${ }^{11}$ A novel observation of this study is an apparent bone marrow and/or hematological defect in Recql $4^{\mathrm{HD}}$. The defects in the RTS mouse model blood cells may be explained by senescence of bone marrow cells. Progressive leukopenia, chronic microcytic hypochromic anemia, myelodysplasia, aplastic anemia and leukemia have been reported in some RTS patients, ${ }^{11}$ and these hematologic disorders are closely associated with dysfunction of bone marrow. $^{52}$ RTS patients experience symptoms in highly proliferative tissue of skin, nails, teeth, blood, intestines and bone. ${ }^{11}$ It is likely that RECQL4 is essential for the viability of highly proliferative cells because of its important role in DNA replication. Therefore, dysfunction of RECQL4 may cause reduced cellular proliferative potential, leading to severe damage in the highly proliferative tissue, as well as lower potential for tissue regeneration. This aspect of RECQL4 dysfunction is likely to have pathological consequences, and may be relevant to understanding clinical features of diseases linked to the loss of RECQL4, BLM and WRN. 


\section{Materials and Methods}

Cell culture. Human primary fibroblast cell lines GM00969 (Passage 19) and GM05565 (Passage 11) were purchased from Coriell Institute for Medical Research and cultured in MEM minimal medium (Gibco, Grand Island, NY, USA) supplemented with $15 \%$ fetal bovine serum (Sigma-Aldrich, St. Louis, MO, USA), $1 \times$ vitamin (Gibco), $1 \times$ L-glutamine (Gibco), $1 \times$ non-essential amino acids (Gibco), $100 \mathrm{U} / \mathrm{ml}$ penicillin (Gibco) and $10 \mathrm{mg} / \mathrm{ml}$ streptomycin (Gibco) in an atmosphere of $20 \% \mathrm{O}_{2}$ and $5 \% \mathrm{CO}_{2}$, except where noted otherwise, $3 \% \mathrm{O}_{2}$ was used.

shRNA-mediated knockdown. Plasmid pLKO.1 harboring shRNA targeting RECQL1, BLM, WRN, RECQL4 and RECQL5 were obtained from SigmaAldrich. The control shRNA in pLKO.1, deposited in Addgene (Cambridge, MA, USA) by Dr. Sabatini, ${ }^{34}$ was purchased from Addgene. The detailed information of these shRNA is listed in Supplementary Table S2. Then, five lentiviruses transcribing shRNA against each RecQ as well as the control shRNA were constructed and used as described previously. ${ }^{10,53,54}$ For stable knockdown, $60-70 \%$ confluent cells were incubated with lentivirus for 2 days in complete medium with $8 \mu \mathrm{g} / \mathrm{ml}$ polybrene. The cells were selected with $3 \mu \mathrm{g} / \mathrm{ml}$ puromycin (Invitrogen, Grand Island, NY, USA) for another 4 days, and then were ready for use in the experiments. Medium was changed once during the antibiotic selection. For different $\mathrm{O}_{2}$ concentration treatment, the cells were incubated with lentivirus for 2 days in $3 \% \mathrm{O}_{2}$ incubator and later split into two parts for another 4 days selection in $20 \% \mathrm{O}_{2}$ or $3 \% \mathrm{O}_{2}$ conditions before experiments.

siRNA-mediated knockdown. The siRNAs targeting RECQL1, RECQL4 and RECQL5 helicases were designed and synthesized as described in previous studies. ${ }^{10,54,55}$ The siRNAs against BLM and WRN were designed in this study. The mock siRNA ON-TARGET plus non-targeting siRNA no. 1 was obtained from Dharmacon (GE Biosciences, Pittsburgh, PA, USA). All sequence information of siRNA is also listed in Supplementary Table S2. The siRNAs were delivered into cells with InterferlN (Polyplus transfection, Illkirch, France) according to the manufacturer's protocol. The cells were ready for use in experiments $72 \mathrm{~h}$ after transfection.

Western blotting. Stable knockdown or scramble-treated cells were harvested and washed with PBS, and then suspended in $1 \times$ RIPA buffer (Cell Signaling, Danvers, MA, USA), followed by sonication on ice. After removal of cell debris by centrifugation, protein concentrations were determined with Bio-Rad Protein Assay Kit (Bio-Rad, Hercules, CA, USA). Proteins were denatured and separate in $4-15 \%$ SDS-PAGE, and then transferred to PVDF membrane. After blocking with $5 \%$ nonfat milk, primary antibodies were added and incubated overnight at $4^{\circ} \mathrm{C}$. The HRPconjugated secondary antibodies (GE Biosciences; sleep anti-rabbit lgG or goat antimouse $(g G$ ) were then added to PVDF membrane. Finally, membranes were developed with Pierce ECL western blotting substrate (Thermo-Fisher, Rockford, IL, USA) and observed with Bio-Rad ChemiDoc XRS imaging system. The intensity of bands was quantified with Image Lab 4.1 software (Bio-Rad). Primary antibodies are listed as follows: RECQL1 antibody (sc25547), p53 antibody (sc-126), actin antibody (sc-1616) and p21 antibody (sc-817X) from Santa Cruz (Dallas, TX, USA); BLM antibody (ab2179), anti-ATM antibody (ab32420) and anti-ATM (phospho-S1981) antibody (2152-1), $\gamma$ H2A.X antibody (ab11174) from Abcam (Cambridge, MA, USA); p16 antibody (51-1325GR) from BD Pharmingen (BD Biosciences, Franklin Lakes, NJ, USA); Flag antibody (F1804) from Sigma-Aldrich; anti-H2A.X antibody (2595) and anti-p53 (phospho-S15) antibody (9284) from Cell Signaling; mouse anti-WRN monoclonal antibody, ${ }^{56}$ rabbit anti-RECQL4 polyclonal antibody ${ }^{32}$ and rabbit antiRECQL5 antibody ${ }^{33}$ were prepared in this lab.

Flow cytometry. Cell cycle and apoptosis studies were performed according to the procedures mentioned elsewhere by flow cytometry. ${ }^{57}$ In brief, primary fibroblasts were knockdown with shRNA against different RecQ helicases as described above, and these cells were harvested, washed with PBS and fixed with $75 \%$ ethanol overnight. The second day, cells were washed with PBS, and treated with $0.2 \mathrm{mg} / \mathrm{ml}$ RNase A for $30 \mathrm{~min}$. Finally, cells were stained with $5 \mu \mathrm{g} / \mathrm{ml} \mathrm{PI}$ (Invitrogen) for $15 \mathrm{~min}$, and the fluorescence was analyzed using a Accuri $\mathrm{C} 6$ flow cytometer (BD Biosciences) at $488 \mathrm{~nm}$. Apoptosis was measured using an Apoptosis Kit (No. V-13245; Invitrogen) as per the manufacturer's instruction. Generally, knockdown cells were harvested, washed with PBS and then stained with Annexin $\mathrm{V}$ and $\mathrm{PI}$, and then analyzed on a $\mathrm{C} 6$ flow cytometer for data collection. Data were analyzed by FCS Express 4 software (De Novo Software, Los Angeles, CA, USA). Three biological repeats were applied here, and Student's $t$-test were performed to examine the statistical significant difference.
Cell proliferation assay. Roche WST-1 Kit (Roche Diagnostics, Indianapolis, IN, USA) was applied to measure cell proliferation of the RecQ-depleted cells and the scramble-treated cells according to the manufacturer's instruction. Approximately $1 \times 10^{4}$ cells were seeded in 96-well plates and growth was monitored using Benchmark plus microplate spectrophotometer (Bio-Rad) every other day. Reading data were normalized to the reading of the first day. Three independent assays were performed.

SA- $\beta$-gal staining. SA- $\beta$-gal staining was performed with Senescence $\beta$-Galactosidase Staining Kit according to the manufacturer's instructions (Cell Signaling). Briefly, after washing with PBS, cells were fixed with $2 \%$ formaldehyde and $0.2 \%$ glutaraldehyde in PBS for $15 \mathrm{~min}$ at room temperature. The fixed cells were incubated with X-gal staining solution at $37^{\circ} \mathrm{C}$ for $16 \mathrm{~h}$ after PBS washing. Cells were visualized and pictured with Zeiss PALM laser capture microdissection microscope (Zeiss, Oberkochen, Germany). The percentages of positively stained cells were calculated based on three replicates. Three male Recq $14^{\mathrm{HD}}$ mice at 12 months as well as their sibling wild-type mice were analyzed for quantification of senescence on mouse tail sections. Sections of $7 \mu \mathrm{m}$ from OCT-embedded frozen tails were fixed and stained as described above, and then stained sections were observed under Zeiss PALM system. Over 100 hair follicles (per mouse) were observed and photographed, and the percentage of positive-staining hair follicles was calculated. Student's $t$-test was performed to examine the statistically significant difference between the samples.

Immunofluorescence microscope. Stable knockdown and the control cells were plated onto chambered slides. On the next day, the cells were washed with PBS, and fixed with $4 \%$ paraformaldehyde, and then permeabilized with $0.2 \%$ Triton X-100 for $5 \mathrm{~min}$ at room temperature. The cells were washed with PBS and blocked with $5 \%$ FBS overnight at $4{ }^{\circ} \mathrm{C}$. Rabbit polyclonal anti-53BP1 antibody (Novus Biologicals, Littleton, CO, USA; Cat. No.: NB100-305) and mouse monoclonal anti-PML antibody (Millipore, Billerica, MA, USA; Cat. No.: 05-718) were added to the cells in an orderly manner. Slides were washed and then the bound antibodies were detected with the secondary antibodies, Alexa-conjugated 488 donkey anti-rabbit IgG and 594 donkey anti-mouse IgG (Molecular Probe, Grand Island, NY, USA). A drop of antifade reagent containing DAPI (Invitrogen) was added to the slides to stain nuclear DNA. The slides were observed and photographed with Zeiss Axiovert 200M flourescence microscope equipped with AxioCam HRM camera and over 200 cells (per sample) were incorporated into the analysis. For $\gamma \mathrm{H} 2 \mathrm{~A} . \mathrm{X}$ foci, rabbit polyclonal to $\gamma \mathrm{H} 2 \mathrm{~A} . \mathrm{X}$ (Abcam; Cat. No.: ab11174) was used.

RNA extraction, quantitative PCR and microarray. Total RNA from five $\operatorname{RecQ}$ helicase stable knockdown and control cells were prepared with RNeasy Kit from Qiagen (Valencia, CA, USA) according to the manufacturer's instruction. For RT-PCR, $100 \mathrm{ng}$ RNA was reversely transcripted with iScript cDNA Synthesis Kit (Bio-Rad) and the resulting cDNA was submitted for quantitative Real-time PCR using iQ SYBR Green Supermix (Bio-Rad). Primers for the five RecQ helicase genes and GAPDH are listed in Supplementary Table S2. Global transcriptional changes due to deficiency of RecQ helicases in primary fibroblast cells were investigated by microarray assay as described previously. ${ }^{27}$ Raw microarray intensity data were initially filtered by detection $P$-values $\leq 0.02$ at least on one sample, and normalized by $Z$ normalization as described previously. ${ }^{58}$ Sample quality was analyzed by combined processes, including correlation/ scatterplots, principal component analysis and gene sample Z-score-based hierarchical clustering to exclude possible outliers. Genes with larger variances within each comparison group were firstly pairwise eliminated by ANOVA tests independent one way based on each sample group. The threshold values for positively identified genes were as follows: $Z$-test $P$-value $\leq 0.05$, the $\mid Z$ ratiol $\geq 1.5$ and the false discovery ratio $\leq 0.3$. In addition, signal average intensity has to be non-negative. Gene set enrichment analysis was used to determine affected pathways in common among all groups as reported. ${ }^{59}$ The pathways were obtained from MIT Broad Institute (Cambridge, MA, USA). Hierarchy clustering was performed to identify clustering within groups.

Senescence complementation assay using RECQL4 fragments. To investigate the function of RECQL4 domains in preventing cellular senescence, plasmids harboring RECQL4 fragments were constructed. A 3X-Flagtagged RECQL4 construct, pCMV-Tag4A-RQ4-3X-Flag, was PCR linearized with the following primers pCMV4A-3X-Flag-fwd and pCMV4A-3X-Flag-rev, 
phosphorylated and blunt-end ligated. The resulting plasmid, pCMV-Tag4A-3X-Flag, contains the insertion DYKDHDGDYKDHDI in front of the existing Flag-tag DYKDDDDK, thereby generating the triple Flag epitope. Human RECQL4 gene was PCR-amplified from pENTR221-RQ4 plasmid (provided by Dr. Mohammad Hedayati) using primers: RecQ4-Notl-Kozak-fwd and RECQ4-Xhol-nostop-rev, and inserted into PCMV-Tag4A-3X-Flag vector with Notl and Xhol digestion, generating pCMV-Tag4A-RQ4-3X-Flag. RECQL4 CDNA encoding these fragments were amplified with PCR using primers as shown in Supplementary Table S2 and then cloned into pCMV-Tag4A-3X-Flag. Owing to the fact that not all fragments contain a nuclear localization signal (NLS), we elected to add an artificial NLS to all fragments to exclude the possibility that any of the fragments might be mislocalized to the cytosol. RECQL4 helicase dead mutant K508M was reported previously ${ }^{21}$ and cut and pasted into linearized pCMV-Tag4A-3X-Flag. All constructs were confirmed by sequencing. For senescence complementation assays, the plasmids harboring NLS-tagged RECQL4 fragments, as well as RECQL4, were first transfected into human primary fibroblast cells GM05565 at passage 11, and an siRNA targeting the $3^{\prime}$-UTR region of endogenous RECQL4 (see the sequence of the siRNA in Supplementary Table S2) was then transfected into these cells in the following day to deplete endogenous RECQL4 mRNA. Four days after siRNA transfection of siRNA, the cells were processed for SA- $\beta$-gal staining and western blotting.

Rederivation of RTS mouse model by cross-fostering. Upon receipt of Recql4 HT mice from Dr. Guangbin Luo (Case Western Reserve University, Cleveland, $\mathrm{OH}),{ }^{39}$ the mice were placed into quarantine. Male Recq/4 $\mathrm{HT}$ mice were then mated to female C57BL/6J mice for at least three generations. The generated homozygous Recq/4 mutant mice were designated Recql $4^{\mathrm{HD}}$. The mice contain a PGKHprt mini-gene cassette inserted within exons 9-13, resulting in the deletion of $80 \%$ of the genomic DNA that encodes the helicase domain. ${ }^{39}$ The mice were housed at the National Institute on Aging (NIA) under standard conditions and fed standard animal chow. All animal procedures and protocols were approved by the NIA Animal Care and Use Committee and performed in accordance with National Institutes of Health Guidelines for the Care and Use of Laboratory Animals (National Institutes of Health Publication 85-23, National Institutes of Health, Bethesda, MD, USA).

Extraction and culture of mouse tail fibroblast cells and bone marrow cells. For preparation of primary fibroblast cells, a $3-\mathrm{cm}$-long tail tips from three pairs of wild-type and Recql 4 mice were sniped and washed with $70 \%$ ethanol and PBS, and then transferred to the prewarmed complete medium containing DMEM, 10\% FBS, $100 \mathrm{U} / \mathrm{ml}$ penicillin/streptomycin and $0.25 \mu \mathrm{g} / \mathrm{ml}$ fungizone. Tail tips were diced to small squares and digested with collagenase for $24 \mathrm{~h}$ at $37{ }^{\circ} \mathrm{C}$ in an atmosphere of $3 \% \mathrm{O}_{2}$ and $5 \% \mathrm{CO}_{2}$. Cells were dislodged from tails by vigorous pipetting and then cultured in fresh complete medium for 3 days. For oxygen stress experiment, the fibroblast cells at passage two were cultured in both $20 \%$ and $3 \% \mathrm{O}_{2}$ conditions for 3 days and processed for SA- $\beta$-gal staining. Bone marrow cells were prepared from femurs and tibias of age-matched-type mice as described previously. ${ }^{60}$ The bone marrow cells were cultured in Iscove's modified Dulbecco's medium (Invitrogen) supplemented with $20 \%$ fetal calf serum, $200 \mathrm{U} / \mathrm{ml}$ interleukin 6 (Peprotech, Rocky Hill, NJ, USA) and $100 \mathrm{ng} / \mathrm{ml}$ stem cell factor (Peprotech). These cells were processed for experiments at passage two.

Mouse tail hair counting and histopathologic analysis. For counting tail hair, three male Recql $4^{\mathrm{HD}}$ mice at 12 months as well as their sibling wild-type mice were analyzed. The tail skin with hair was unfolded and the hair was counted under a microscope. Student's $t$-test was applied to measure the statistical difference. NIH Division of Veterinary Resources carried out comprehensive standardized gross and histopathologic analyses of four wildtype mice and three Recq $14^{\mathrm{HD}}$ mice at the age of 4 months, including the analyses of organ weights, serum chemistries and hematology. Blood samples were collected via cardiac puncture under isoflurane anesthesia and placed in Microvette (tm) $100 \mu \mathrm{m}$ EDTA tubes. Blood samples were analyzed via a Drew Scientific Hemavet 1700FS Hematology machine (Erba Diagnostics, Dallas, TX, USA). Blood values for each parameter were compared for statistical difference using a $t$-test assuming unequal variance.

\section{Conflict of Interest}

The authors declare no conflict of interest.
Acknowledgements. Mice were rederived from a pair of mice from Dr. Guangbin Luo of Case Western Reserve University. We thank Dr. Elin Lehrmann from the Microarray faculty of NIA for her assistance in performing microarray. We thank Vickie Hoffmann from NIH Division of Veterinary Resources for the comprehensive gross and histopathologic analyses. We also thank Jingyan Tian, Joseph Hsu and Lale Dawut for their technical support. We also want to thank Drs. Beverly Baptiste, Raghavendra Shamanna, Mengxia Li and Takashi Tadokoro at the NIA for their critical discussions. This research was supported entirely by the Intramural Research Program of the NIH, NIA.

1. Hayflick L. The limited in vitro lifetime of human diploid cell strains. Exp Cell Res 1965; 37 : 614-636

2. d'Adda di Fagagna F. Cellular senescence and cellular longevity: nearly 50 years on and still working on it. Exp Cell Res 2008; 314: 1907-1908.

3. Rodier F, Campisi J. Four faces of cellular senescence. J Cell Biol 2011; 192: 547-556.

4. Rodier F, Munoz DP, Teachenor R, Chu V, Le O, Bhaumik D et al. DNA-SCARS: distinct nuclear structures that sustain damage-induced senescence growth arrest and inflammatory cytokine secretion. J Cell Sci 2011; 124(Part 1): 68-81.

5. Campisi J. Aging, cellular senescence, and cancer. Annu Rev Physiol 2013; 75: 685-705.

6. Kong $\mathrm{Y}$, Cui $\mathrm{H}$, Ramkumar $\mathrm{C}$, Zhang $\mathrm{H}$. Regulation of senescence in cancer and aging. J Aging Res 2011; 2011: 963172.

7. Collado M, Blasco MA, Serrano M. Cellular senescence in cancer and aging. Cell 2007; 130: 223-233.

8. Bohr VA. Rising from the RecQ-age: the role of human RecQ helicases in genome maintenance. Trends Biochem Sci 2008; 33: 609-620.

9. Chu WK, Hickson ID. RecQ helicases: multifunctional genome caretakers. Nat Rev Cancer 2009; 9: 644-654.

10. Singh DK, Ghosh AK, Croteau DL, Bohr VA. RecQ helicases in DNA double strand break repair and telomere maintenance. Mutat Res 2012; 736: 15-24.

11. Larizza L, Roversi G, Volpi L. Rothmund-Thomson syndrome. Orphanet J Rare Dis 2010; 5: 2

12. Choi D, Whittier PS, Oshima J, Funk WD. Telomerase expression prevents replicative senescence but does not fully reset mRNA expression patterns in Werner syndrome cell strains. FASEB J 2001; 15: 1014-1020.

13. Saito $\mathrm{H}$, Moses RE.. Immortalization of Werner syndrome and progeria fibroblasts. Exp Cell Res 1991; 192: 373-379.

14. Szekely AM, Bleichert F, Numann A, Van Komen S, Manasanch E, Ben Nasr A et al. Werner protein protects nonproliferating cells from oxidative DNA damage. Mol Cell Biol 2005; 25: 10492-10506.

15. Oshima J, Campisi J, Tannock TC, Martin GM. Regulation of c-fos expression in senescing Werner syndrome fibroblasts differs from that observed in senescing fibroblasts from normal donors. J Cell Physiol 1995; 162: 277-283.

16. Tivey HS, Brook AJ, Rokicki MJ, Kipling D, Davis T. p38 (MAPK) stress signalling in replicative senescence in fibroblasts from progeroid and genomic instability syndromes. Biogerontology 2013; 14: 47-62.

17. Hagelstrom RT, Blagoev KB, Niedernhofer LJ, Goodwin EH, Bailey SM. Hyper telomere recombination accelerates replicative senescence and may promote premature aging. Proc Natl Acad Sci USA 2010; 107: 15768-15773.

18. Croteau DL, Singh DK, Hoh Ferrarelli L, Lu H, Bohr VA. RECQL4 in genomic instability and aging. Trends Genet 2012; 28: 624-631.

19. Xu X, Liu Y. Dual DNA unwinding activities of the Rothmund-Thomson syndrome protein, RECQ4. EMBO J 2009; 28: 568-577.

20. Suzuki T, Kohno T, Ishimi Y. DNA helicase activity in purified human RECQL4 protein. J Biochem 2009; 146: 327-335.

21. Rossi ML, Ghosh AK, Kulikowicz T, Croteau DL, Bohr VA. Conserved helicase domain of human RecQ4 is required for strand annealing-independent DNA unwinding. DNA Repair (Amst) 2010; 9: 796-804.

22. Sangrithi MN, Bernal JA, Madine M, Philpott A, Lee J, Dunphy WG et al. Initiation of DNA replication requires the RECQL4 protein mutated in Rothmund-Thomson syndrome. Cell 2005; 121: 887-898.

23. Matsuno $\mathrm{K}$, Kumano M, Kubota $\mathrm{Y}$, Hashimoto $\mathrm{Y}$, Takisawa $\mathrm{H}$. The $\mathrm{N}$-terminal noncatalytic region of Xenopus RecQ4 is required for chromatin binding of DNA polymerase alpha in the initiation of DNA replication. Mol Cell Biol 2006; 26: 4843-4852.

24. Thangavel S, Mendoza-Maldonado R, Tissino E, Sidorova JM, Yin J, Wang W et al. Human RECQ1 and RECQ4 helicases play distinct roles in DNA replication initiation. Mol Cell Biol 2010; 30: 1382-1396.

25. Petkovic M, Dietschy T, Freire R, Jiao R, Stagljar I. The human Rothmund-Thomson syndrome gene product, RECQL4, localizes to distinct nuclear foci that coincide with proteins involved in the maintenance of genome stability. J Cell Sci 2005; 118(Part 18): 4261-4269.

26. Fan W, Luo J. RecQ4 facilitates UV light-induced DNA damage repair through interaction with nucleotide excision repair factor xeroderma pigmentosum group A (XPA). J Biol Chem 2008; 283: 29037-29044. 
27. Schurman SH, Hedayati M, Wang Z, Singh DK, Speina E, Zhang Y et al. Direct and indirect roles of RECQL4 in modulating base excision repair capacity. Hum Mol Genet 2009; 18: 3470-3483.

28. Woo LL, Futami K, Shimamoto A, Furuichi Y, Frank KM. The Rothmund-Thomson gene product RECQL4 localizes to the nucleolus in response to oxidative stress. Exp Cell Res 2006; 312: 3443-3457.

29. Jin W, Liu H, Zhang Y, Otta SK, Plon SE, Wang LL. Sensitivity of RECQL4-deficient fibroblasts from Rothmund-Thomson syndrome patients to genotoxic agents. Hum Genet 2008; 123: 643-653

30. Ferrarelli LK, Popuri V, Ghosh AK, Tadokoro T, Canugovi C, Hsu JK et al. The RECQL4 protein, deficient in Rothmund-Thomson syndrome is active on telomeric D-loops containing DNA metabolism blocking lesions. DNA Repair (Amst) 2013; 12: 518-528.

31. Ghosh AK, Rossi ML, Singh DK, Dunn C, Ramamoorthy M, Croteau DL et al. RECQL4, the protein mutated in Rothmund-Thomson syndrome, functions in telomere maintenance. J Biol Chem 2012; 287: 196-209.

32. Croteau DL, Rossi ML, Canugovi C, Tian J, Sykora P, Ramamoorthy M et al. RECQL4 localizes to mitochondria and preserves mitochondrial DNA integrity. Aging Cell 2012; 11: 456-466.

33. De S, Kumari J, Mudgal R, Modi P, Gupta S, Futami K et al. RECQL4 is essential for the transport of p53 to mitochondria in normal human cells in the absence of exogenous stress. J Cell Sci 2012; 125(Part 10): 2509-2522.

34. Sarbassov DD, Guertin DA, Ali SM, Sabatini DM. Phosphorylation and regulation of Akt/ PKB by the rictor-mTOR complex. Science 2005; 307: 1098-1101.

35. Debacq-Chainiaux F, Erusalimsky JD, Campisi J, Toussaint O. Protocols to detect senescence-associated beta-galactosidase (SA-betagal) activity, a biomarker of senescent cells in culture and in vivo. Nat Protoc 2009; 4: 1798-1806.

36. Hampel B, Wagner M, Teis D, Zwerschke W, Huber LA, Jansen-Durr P. Apoptosis resistance of senescent human fibroblasts is correlated with the absence of nuclear IGFBP-3. Aging Cell 2005; 4: 325-330.

37. Sherwood SW, Rush D, Ellsworth JL, Schimke RT. Defining cellular senescence in IMR-90 cells: a flow cytometric analysis. Proc Natl Acad Sci USA 1988; 85: 9086-9090.

38. Mao Z, Ke Z, Gorbunova V, Seluanov A. Replicatively senescent cells are arrested in G1 and G2 phases. Aging (Albany, NY) 2012; 4: 431-435.

39. Mann MB, Hodges CA, Barnes E, Vogel H, Hassold TJ, Luo G. Defective sister-chromatid cohesion, aneuploidy and cancer predisposition in a mouse model of type II RothmundThomson syndrome. Hum Mol Genet 2005; 14: 813-825.

40. Hoki Y, Araki R, Fujimori A, Ohhata T, Koseki H, Fukumura R et al. Growth retardation and skin abnormalities of the Recql4-deficient mouse. Hum Mol Genet 2003; 12 : 2293-2299.

41. Davies SL, North PS, Hickson ID. Role for BLM in replication-fork restart and suppression of origin firing after replicative stress. Nat Struct Mol Biol 2007; 14: 677-679.

42. Bernstein KA, Gangloff S, Rothstein R. The RecQ DNA helicases in DNA repair. Annu Rev Genet 2010; 44: 393-417.

43. Popuri V, Tadokoro T, Croteau DL, Bohr VA. Human RECQL5: guarding the crossroads of DNA replication and transcription and providing backup capability. Crit Rev Biochem Mol Biol 2013; 48: 289-299.

44. Hu Y, Raynard S, Sehorn MG, Lu X, Bussen W, Zheng L et al. RECQL5/Recql5 helicase regulates homologous recombination and suppresses tumor formation via disruption of Rad51 presynaptic filaments. Genes Dev 2007; 21: 3073-3084.

45. Sharma S, Stumpo DJ, Balajee AS, Bock CB, Lansdorp PM, Brosh RM Jr et al. RECQL, a member of the RecQ family of DNA helicases, suppresses chromosomal instability. Mol Cell Biol 2007; 27: 1784-1794

46. Davis T, Tivey HS, Brook AJ, Grimstead JW, Rokicki MJ, Kipling D. Activation of p38 MAP kinase and stress signalling in fibroblasts from the progeroid Rothmund-Thomson syndrome. Age (Dordr) 2013; 35: 1767-1783.
47. Abe T, Yoshimura A, Hosono Y, Tada S, Seki M, Enomoto T. The N-terminal region of RECQL4 lacking the helicase domain is both essential and sufficient for the viability of vertebrate cells. Role of the N-terminal region of RECQL4 in cells. Biochim Biophys Acta 2011; 1813: 473-479.

48. Croteau DL, Rossi ML, Ross J, Dawut L, Dunn C, Kulikowicz T et al. RAPADILINO RECQL4 mutant protein lacks helicase and ATPase activity. Biochim Biophys Acta 2012; 1822: $1727-1734$

49. Jensen MB, Dunn CA, Keijzers G, Kulikowicz T, Rasmussen LJ, Croteau DL et al. The helicase and ATPase activities of RECQL4 are compromised by mutations reported in three human patients. Aging (Albany, NY) 2012; 4: 790-802.

50. Marino F, Vindigni A, Onesti S. Bioinformatic analysis of RecQ4 helicases reveals the presence of a RQC domain and a $\mathrm{Zn}$ knuckle. Biophys Chem 2013; 177-178: 34-39.

51. Kohzaki M, Chiourea M, Versini G, Adachi N, Takeda S, Gagos S et al. The helicase domain and C-terminus of human RecQL4 facilitate replication elongation on DNA templates damaged by ionizing radiation. Carcinogenesis 2012; 33: 1203-1210.

52. Camitta BM, Storb R, Thomas ED. Aplastic anemia (first of two parts): pathogenesis, diagnosis, treatment, and prognosis. N Engl J Med 1982; 306: 645-652.

53. Ramamoorthy M, Tadokoro T, Rybanska I, Ghosh AK, Wersto R, May A et al. RECQL5 cooperates with Topoisomerase II alpha in DNA decatenation and cell cycle progression. Nucleic Acids Res 2012; 40: 1621-1635.

54. Sharma S, Brosh RM Jr. Human RECQ1 is a DNA damage responsive protein required for genotoxic stress resistance and suppression of sister chromatid exchanges. PLoS One 2007; 2: e1297.

55. Kanagaraj R, Huehn D, MacKellar A, Menigatti M, Zheng L, Urban V et al. RECQ5 helicase associates with the C-terminal repeat domain of RNA polymerase II during productive elongation phase of transcription. Nucleic Acids Res 2010; 38: 8131-8140.

56. Cheng WH, Muftic D, Muftuoglu M, Dawut L, Morris C, Helleday T et al. WRN is required for ATM activation and the S-phase checkpoint in response to interstrand cross-link-induced DNA double-strand breaks. Mol Biol Cell 2008; 19: 3923-3933.

57. Fang $\mathrm{EF}$, Zhang $\mathrm{CZ}$, Zhang L, Fong WP, $\mathrm{Ng} \mathrm{TB}$. In vitro and in vivo anticarcinogenic effects of RNase MC2, a ribonuclease isolated from dietary bitter gourd, toward human liver cancer cells. Int J Biochem Cell Biol 2012; 44: 1351-1360.

58. Cheadle C, Vawter MP, Freed WJ, Becker KG. Analysis of microarray data using Z score transformation. J Mol Diagn 2003; 5: 73-81.

59. Kim SY, Volsky DJ. PAGE: parametric analysis of gene set enrichment. BMC Bioinform 2005; 6: 144.

60. Vallabhaneni $\mathrm{H}, \mathrm{O}$ 'Callaghan $\mathrm{N}$, Sidorova J, Liu Y. Defective repair of oxidative base lesions by the DNA glycosylase Nth1 associates with multiple telomere defects. PLOS Genet 2013; 9: e1003639.

(c) (i) $\odot$ Cell Death and Disease is an open-access journal (c) ${ }_{\mathrm{BY}} \mathrm{ND}$ published by Nature Publishing Group. This work is licensed under a Creative Commons Attribution-NonCommercialNoDerivs 3.0 Unported License. The images or other third party material in this article are included in the article's Creative Commons license, unless indicated otherwise in the credit line; if the material is not included under the Creative Commons license, users will need to obtain permission from the license holder to reproduce the material. To view a copy of this license, visit http://creativecommons.org/licenses/ by-nc-nd/3.0/ 